\title{
LÓGICA PARACONSISTENTE NA AVALIAÇÃO DE EMPRESAS
}

\author{
Luana Sara Bizatto \\ Universidade Regional de Blumenau - FURB \\ Rua Antônio da Veiga, 140, Blumenau - Itoupava Seca, 89030-003 \\ luanasarabizatto@hotmail.com \\ Nelson Hein \\ Universidade Regional de Blumenau - FURB \\ Rua Antônio da Veiga, 140, Blumenau - Itoupava Seca, 89030-003 \\ hein@furb.br \\ Adriana Kroenke \\ Universidade Regional de Blumenau - FURB \\ Rua Antônio da Veiga, 140, Blumenau - Itoupava Seca, 89030-003 \\ akroenke@furb.br \\ André Luis Korzenowski \\ Universidade do Vale do Rio dos Sinos - UNISINOS \\ Avenida Unisinos, 950, São Leopoldo \\ akorzenowski@unisinos.br
}

\section{RESUMO}

O objetivo da pesquisa consiste em avaliar o grau de viabilidade de empresas do setor de Siderurgia e Metalurgia analisadas por contadores pesquisadores de três instituições universitárias do Sul do Brasil, observando os seus indicadores econômico-financeiros. Participaram da pesquisa seis especialistas, sendo dois pesquisadores e dois auxiliares da área de Finanças de três universidades brasileiras. Verificou-se que a liquidez corrente influenciou negativamente no posicionamento econômico-financeiro da Siderurgia e Metalurgia, em oposição às influências verificadas em outros indicadores como de liquidez seca, rentabilidade sobre os ativos, giro do ativo e prazo médio de renovação de estoques, as quais foram verificadas influências positivas. Estes resultados indicam a necessidade de novas estratégias para este subsetor, com a finalidade de melhorar tanto a saúde financeira, como o posicionamento econômico-financeiro dessas empresas.

Palavra-chave: Desempenho; Siderurgia; Metalurgia; Indicadores; Lógica paraconsistente.

\begin{abstract}
The objective of the research is to evaluate the degree of viability of companies in the Steel and Metallurgy sector analyzed by research accountants from three university institutions in southern Brazil, observing their economic and financial indicators. Six specialists participated in the research, two researchers and two finance assistants from three Brazilian universities. Current liquidity had a negative influence on the economic and
\end{abstract}


financial positioning of Steel and Metallurgy, as opposed to influences on other indicators such as dry liquidity, return on assets, asset turnover and average period of inventory renewal positive influences were verified. These results indicate the need for new strategies for this subsector in order to improve both the financial health and the economic and financial positioning of these companies.

Keywords: Performance; Steel industry; Metallurgy; Indicators; Paraconsistent logic.

\section{Como Citar:}

BIZATTO, Luana Sara; HEIN, Nelson; KROENKE, Adriana; KORZENOWSKI, Andre Luis. Lógica paraconsistente na avaliação de empresas. In: SIMPÓSIO DE PESQUISA OPERACIONAL E LOGÍSTICA DA MARINHA, 19., 2019, Rio de Janeiro, RJ. Anais [...]. Rio de Janeiro: Centro de Análises de Sistemas Navais, 2019.

\section{INTRODUÇÃO}

Conforme Falconi (2017), as ferramentas de gestão na Siderurgia precisam ser aprimoradas, porém um dos desafios que emergem nesse subsetor é a implementação de grandes planos de investimento. Falconi (2017) cita como algumas das soluções o aumento do Ebitda, ganhos na produtividade por meio da padronização de processos operacionais, melhoria da qualidade dos produtos, redução dos desvios orçamentários e também a otimização do desenvolvimento e implementação de projetos (prazos, custo e qualidade).

Entretanto, a avaliação das informações econômico-financeiras de uma empresa pode sugerir qual seu potencial em receber futuros investimentos (AGUIAR; CORRAR; BATISTELLA, 2004). Contudo, o sucesso ou fracasso de um determinado projeto pode diferir entre as partes interessadas, ou seja, seus pontos de vista sobre o desempenho podem envolver subjetividade. Aliás, nem sempre a tomada de decisão sobre o desempenho consiste em priorizar a maximização do valor da empresa, devido a impressões pessoais, sentimentos e opiniões, ou seja, as escolhas são subjetivas (FERNANDES; MAZZIONI, 2015).

Objetivando escores fidedignos do desempenho de empresas, é importante a integração de indicadores (GASPARETTO, 2004). Esta síntese pode ser feita por diversas maneiras, contudo a percepção e interpretação da informação contábil por parte de contadores especialistas depende da sua formação, visão e suas influências teórico-práticas. Neste contexto, o uso da Lógica Paraconsistente permite realizar uma forma de análise integrada entre os indicadores. Conforme Bortoluzzi (2009), a utilização de somente um indicador não é o suficiente à explicação do desempenho, como também a utilização de muitos indicadores tende a confundir os usuários. Portanto, importa que cada setor de atuação analise quais são os indicadores mais relevantes à análise da posição da empresa (SOARES, 2006; FUENMAYOR; ANGULO, 2008). Dessa forma, tem-se como questão de pesquisa: qual é o grau de viabilidade econômico-financeira atribuída por contadores pesquisadores das empresas do setor de Siderurgia e Metalurgia, sintetizado e mensurado por meio da lógica paraconsistente anotada? Assim, o objetivo da pesquisa consiste em avaliar o grau de viabilidade de empresas do setor de Siderurgia e Metalurgia analisadas por contadores pesquisadores de três instituições universitárias do Sul do Brasil, observando os seus indicadores econômico-financeiros.

A pesquisa se justifica primeiramente devido ao diminuto número de investigações que utilizam os indicadores econômico-financeiros na avaliação de empresas do setor de Siderurgia e Metalurgia. Além disso, deve-se destacar que há uma crise mundial do excesso de capacidade de produção da indústria siderúrgica, devido ao crescimento da produção 
siderúrgica chinesa, a qual atingiu até países desenvolvidos (THE ECONOMIST, 2016) havendo, inclusive, uma redução na produção latino-americana de aço nas últimas décadas. Além das dificuldades de mercado verificadas no setor da Siderurgia e Metalurgia, no Brasil são perceptíveis ainda limitações como: política econômica governamental baseada na moeda valorizada, falta de uma política industrial específica para o subsetor, o que possivelmente tende a dificultar a melhora do desempenho (POSO, 2015).

\section{SIDERURGIA E METALURGIA}

Considera-se importante averiguar o posicionamento econômico-financeiro de empresas de Siderurgia e Metalurgia, visto que a tecnologia é cada vez mais avançada e o setor depende da eficiência das operações de transporte em toda a cadeia, desde a jazida de minério até o usuário final do aço (SIDERURGIA BRASIL, 2011; LIBERTÁ, 2015). Conforme Siderurgia Brasil (2011), a logística de movimentação de materiais sempre foi um fator fundamental à garantia de bons resultados na Siderurgia. Especificamente, o transporte precisa ser executado com eficiência e com o menor custo possível, levando a maior necessidade de equipamentos modernos e sistemas de gerenciamento avançados (SIDERURGIA BRASIL, 2011).

A Siderurgia e Metalurgia se subdivide em três segmentos: artefatos de ferro e aço, artefatos de cobre e siderurgia (BM\&FBOVESPA, 2016). Especificamente a Metalurgia está relacionada aos processos de extração, fundição, fabricação e tratamento dos metais e ligas, em que se podem destacar: cobre, alumínio, níquel, estanho, zinco e aço (MME, 2011).

O setor metalúrgico apresenta uma considerável importância para o cenário econômico brasileiro, pois tem sua relevância em outras atividades presentes no país como a construção civil, bens de capital e indústria automobilística (MME, 2011; 2013; 2016). Como esse setor está presente na cadeia de valor de várias organizações, este segmento pode servir como um colchão amortecedor de impactos da crise, a fim de que sejam reduzidos os efeitos negativos em grandes empresas, e assumindo importância à estabilidade econômica (LEITE, 2014).

Sobre o setor siderúrgico, este é conhecido como Metalurgia do Aço (MME, 2011), ou ainda, pode ser dito que é o ramo da Metalurgia o qual está voltado para o tratamento de aços e de ferros fundidos (SILVA, 2014). Entre as siderúrgicas, a CNM (2012) informa que a Gerdau, Usiminas e a Sid Nacional estão alocadas entre as melhores posições no ranking mundial. De maneira geral, a atividade siderúrgica é reconhecida como complexa, pois é necessário o uso intensivo de energia, grande aporte de capital e a maturação do investimento geralmente é lenta. Contudo, no Brasil a produção de produtos e subprodutos ainda é simples, o que por sua vez geram menos valor, apesar de ser constatado que há um aumento na participação de produtos mais nobres na produção siderúrgica nacional (CNM, 2012).

Conforme informações da Indústria Aço Brasil (2015), a siderurgia brasileira tem como principal objetivo a participação no comércio mundial de aço, visando desta forma, o desenvolvimento sustentável do país. Recentemente a China é a maior produtora e consumidora no setor siderúrgico (World Steel Association, 2013), contudo deve-se considerar que o Brasil atualmente tem o maior parque industrial de aço da América do Sul, e também é considerado o maior produtor da América Latina. Especialmente em 2014, o Brasil esteve em sexto lugar como exportador líquido de aço, e como nono em produtor de aço no mundo, e em 2015 alcançou a oitava posição do ranking mundial como exportador no setor metalúrgico (MME, 2016).

\section{LÓGICA PARACONSISTENTE}

O pensamento lógico Ocidental foi formado pelas leis da Lógica Clássica, ou seja, pela lei da não-contradição. Essa Lógica Clássica foi criada e sustentada por rígidas leis e está baseada em um raciocínio binário, na qual suas declarações podem ser falsas ou verdadeiras, 
mas não podem ser parcialmente verdadeiras e parcialmente falsas (CARVALHO; ABE, 2011). Muitas vezes são encontradas dificuldades em estabelecer limites para serem feitas afirmativas ou negativas sobre a qualidade das coisas. Os limites entre o "Falso" e "Verdadeiro" são incertos, ambíguos, indefinidos e contraditórios, pois muitas afirmações não podem simplesmente serem classificadas em ou"verdadeiras" ou "falsas". Assim, a Lógica Não-Clássica busca dar respostas mais satisfatórias a problemas relacionados com situações em que não se enquadram as leis da Lógica Clássica (CARVALHO; ABE, 2011).

A Lógica Paraconsistente (LP), como Lógica Não-Clássica, tem como fundamentos teorias inconsistentes e não triviais, ou seja, tem a capacidade de manusear sistemas que são tanto inconsistentes como também não triviais (sem ter o risco de trivialização). Conforme Carvalho e Abe (2011), a Lógica Paraconsistente invalida o princípio da Não Contradição e admite o tratamento de sinais contraditórios. O polonês J. Lukasiewick e o filósofo russo $\mathrm{N}$. A. Vasilév são os precursores da Lógica Paraconsistente, com seus trabalhos seminais publicados por volta de 1910. Os trabalhos desses autores consistiam na possibilidade de uma lógica a qual pudesse considerar as contradições; os seus estudos foram independentes um do outro apesar de serem realizados em mesma época. Contudo, nenhum deles tinham uma visão ampla da lógica não-clássica, diferentemente dos dias de hoje, pois ainda se restringiam à lógica aristotélica tradicional (CARVALHO; ABE, 2011).

Conforme o desenvolvimento da Lógica Paraconsistente com Da Costa, foram sendo realizados estudos relacionados com essa Lógica. Dentre algumas das pesquisas que aplicaram a Lógica Paraconsistente, Torres (2004) desenvolveu um sistema inteligente para o controle de robôs móveis autônomos, e Falquete (2004) utilizou em sistemas de raciocínio baseado em casos para o tratamento de inconsistências. É possível citar também o trabalho de Carvalho, Brunstein e Abe (2004) na tomada de decisão, para avaliação do projeto de implantação de uma fábrica, por meio da utilização da Lógica Paraconsistente.

A evolução tecnológica tem permitido uma melhor aplicação da Lógica Paraconsistente, pois em vez de ignorar certos problemas de inconsistências ao refutar tais como falsas ou confirmando-as como verdadeira, possibilita a modelagem do comportamento humano. Portanto, a Lógica Paraconsistente se diferencia das metodologias de raciocínio quantitativo por fornecer interpretações para informações que são contraditórias (CARVALHO, 2002).

$\mathrm{O}$ cálculo ou lógica é subjacente à teoria $\mathrm{T}$, ou seja: $\mathrm{T}=\left\{\mathrm{A}: \mathrm{T} \vdash_{\mathrm{c}} \mathrm{A}\right\}$. A representa a consequência sintática de $\mathrm{T}$ e nesta condição obrigatoriamente $\mathrm{A}$ deve pertencer a $\mathrm{T}$, ou ainda diz-se que A é "teorema" de T. Conforme Carvalho e Abe (2011), para que uma determinada teoria T seja paraconsistente ela precisa atender a condições: ser inconsistente e não-trivial.

\section{MATERIAIS E MÉTODOS}

Este estudo avaliou 9 empresas da Siderurgia e Metalurgia listadas na BM\&FBovespa usando seis especialistas: dois pesquisadores e dois auxiliares da área de Finanças de três universidades brasileiras. Para a verificação da influência dos indicadores no posicionamento econômico-financeiro das empresas da Siderurgia e Metalurgia, delimitou-se o período de 2011 à 2018. Nesse intuito foi utilizada a lógica paraconsistente para determinação da posição contábil das empresas em análise dentro do reticulado das anotações.

Tecnicamente, a Lógica Paraconsistente consiste em estabelecer proposições e depois parametrizá-las de maneira que possam ser isolados os fatores de maior influência nas decisões, e, com a colaboração de especialistas são realizadas anotações para esses fatores. O objetivo destes procedimentos consiste na consideração dos conceitos de incerteza, inconsistência e de paracompleteza para que as nuances da realidade sejam melhor refletidas e compreendidas (CARVALHO; ABE, 2011). 
As anotações consistem na atribuição de graus de crença $\left(\mu_{1}\right)$ e graus de descrença ( $\mu_{2}$ ) para cada proposição elementar p; esses valores variam de 0 a 1 e são independentes. Conforme Carvalho e Abe (2011), essas anotações estão relacionadas aos conceitos utilizados no LPA, no caso: inconsistência, paracompleteza (indeterminação), noções de verdade e noções de falsidade. $\mathrm{O}$ diagrama de Hasse faz a representação do reticulado na qual pode-se denominar o reticulado das anotações, onde o par $(0 ; 0)$ representado por $\perp$ é o mínimo do

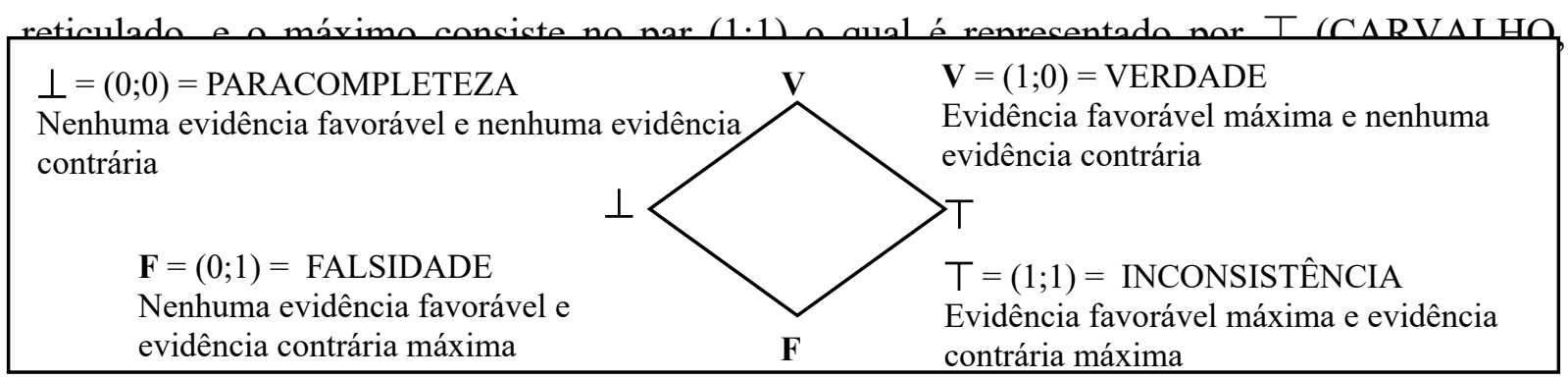

Fonte: Carvalho e Abe (2011).

Figura 1: Reticulado da Lógica Paraconsistente

Desta forma, o par $(1 ; 0)$, que está associado a $p$, representa crença total e ao mesmo tempo nenhuma descrença em p; denomina-se esse estado lógico de verdade (Carvalho, 2002), ou ainda segundo Carvalho e Abe (2011), esta situação representa evidência favorável máxima e nenhuma evidência contrária. Já o par $(0,1)$ revela o oposto: nenhuma crença e descrença total em p, constituindo um estado lógico de falsidade (representação de nenhuma evidência favorável e juntamente apresenta evidência contrária máxima). O par $(1,1)$ significa crença e descrença totais em $\mathrm{p}$, traduzindo um estado lógico chamado de inconsistência (evidência favorável máxima e evidência contrária máxima). Por último tem-se o par $(0,0), \mathrm{o}$ qual indica a ausência total de crença e de descrença em p, ou seja, consiste num estado lógico de indeterminação ou também denominado de estado de paracompleteza (nenhuma evidência favorável e nenhuma evidência contrária) (CARVALHO, 2002).

Conforme Carvalho (2002) e Carvalho e Abe (2011), o estudo da LPA também pode se dar em um Quadrado Unitário no Plano Cartesiano (QUPC), pois esse QUPC é uma forma de representar o reticulado de anotações contendo registros de Graus de Evidência Favorável (Crença) ${ }^{\mu_{1}}$ e Graus de Evidência Desfavorável (Descrença) ${ }_{2}$. A Figura 2 representa o quadrado unitário de plano cartesiano (QUPC).

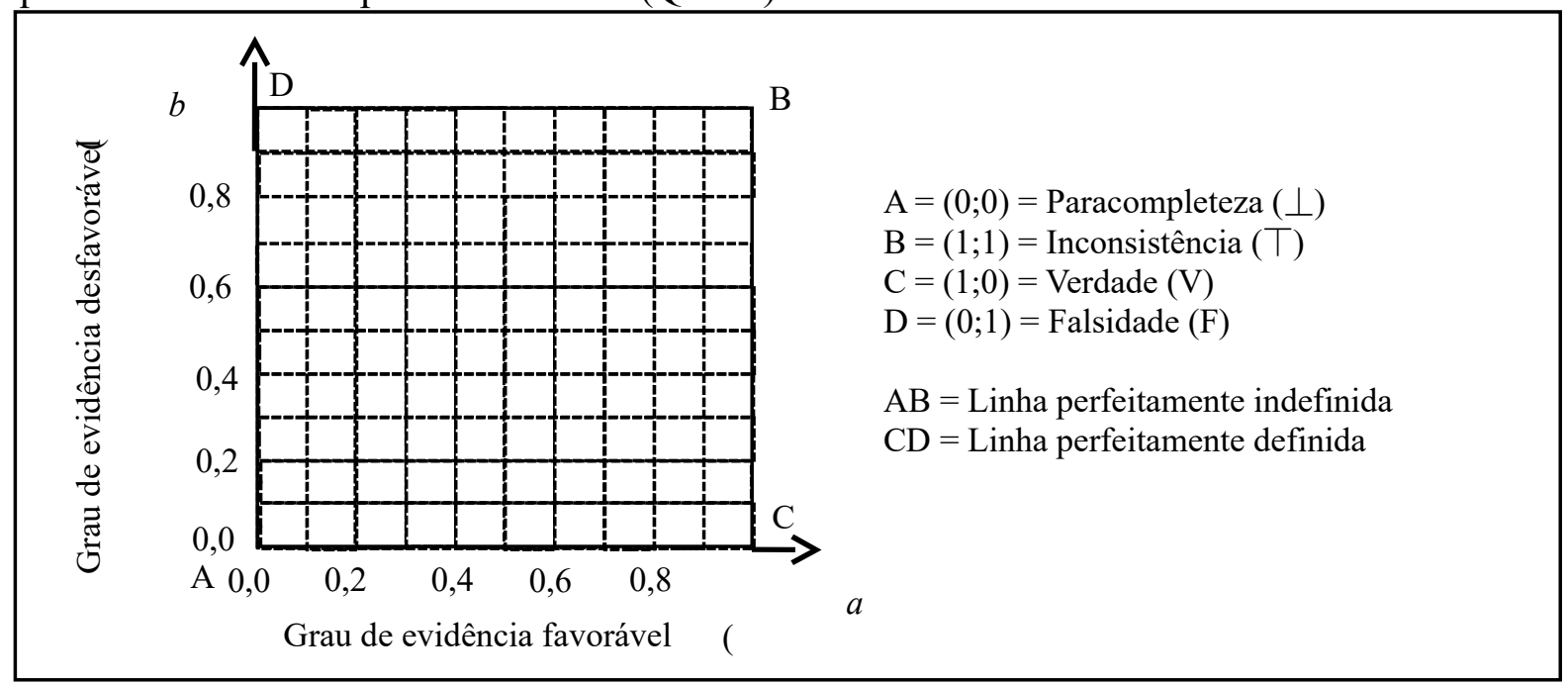

Fonte: Adaptado de Carvalho e Abe (2011, p. 46). 
Figura 2: Quadro unitário das anotações.

Os estados lógicos no reticulado associado aos quatro pontos também são chamados de estados extremos na qual pertencem aos lados AC, AD, CB e DB do QUPC. Por meio desses lados podem ser realizadas interpretações; por exemplo, no lado AC tem-se que o grau de crença varia entre 0 e 1 , contudo o grau de descrença é nulo $\left(\mu_{2}=0\right)$.

Conforme determinado ponto parte de A e avança para C, passa-se de uma situação de total indeterminação (ausência da totalidade de informações), e desta forma alcança-se uma situação considerada perfeitamente definida, ou seja, de crença total assumindo um estado de verdade. Contrariamente, o lado AD do quadrado possui grau de crença nulo $\left(\mu_{1}=0\right)$, e desta vez o grau de descrença $\left(\mu_{2}\right)$ varia de 0 (mínimo) partindo de A até C que representa 1 (máximo), e constitui-se de uma situação perfeitamente definida (isto é, descrença total, ou ainda o valor lógico é chamado de falsidade) (CARVALHO, 2002).

Para o lado CB o grau de crença é igual ao máximo $\left(\mu_{1}=0\right)$ e é mantido constante, contudo pode haver variação no grau de descrença $\left(\mu_{2}\right)$, que inicia no mínimo (zero) em $\mathrm{C}$, até o valor máximo (1) em B. Assim passa-se de um estado lógico de verdade (situação perfeitamente definida) em $\mathrm{C}$, para outro valor lógico de inconsistência na qual tem-se crença e descrença totais ao mesmo tempo (CARVALHO, 2002).

Por fim, o lado DB tem o grau de descrença mantido ao máximo $\left(\mu_{1}=1\right)$, e o grau de crença tem variação do mínimo (zero) ao máximo (1). Logo, há uma passagem de uma situação de falsidade em D para outra situação de inconsistência em B (CARVALHO, 2002).

Deve-se destacar que no QUPC, nenhuma vez haverá uma crença total ou uma descrença total, ou seja, jamais será visto uma situação de verdade absoluta ou de falsidade absoluta, como também não há situação de total inconsistência ou de desinformação completa. Assim para os pontos internos tem-se $0<\mu_{1}<1$ e $0<\mu_{2}<1$ (CARVALHO, 2002).

Devido a algumas empresas não apresentarem informação de valor da ação para todos os anos e também apresentarem patrimônio líquido negativo, optou-se pela exclusão de alguns indicadores econômico-financeiros. Os indicadores econômico-financeiros utilizados suportados pela literatura são apresentados no Quadro 1.

Quadro 1 - Constructo dos indicadores econômico-financeiros

\begin{tabular}{|c|c|c|}
\hline Variável & Fórmula & Autores \\
\hline \multirow{2}{*}{ LG } & Ativo Circulante + Realizável a Longo Prazo & \multirow{2}{*}{ Souza (2007); Matarazzo (2010) } \\
\hline & $\overline{\text { Passivo Circulante + Exigivel a Longo Prazo }}$ & \\
\hline \multirow[b]{2}{*}{$\mathrm{LC}$} & Ativo Circulante & Souza (2007); Matarazzo (2010); \\
\hline & $\overline{\text { Passivo Circulante }}$ & $\begin{array}{l}\text { Gitman, (2010); Ehrhardt e Brigham } \\
\text { (2012) }\end{array}$ \\
\hline \multirow{2}{*}{ LS } & Ativo Circulante - Estoques & Souza (2007); Matarazzo (2010); \\
\hline & Passivo Circulante & $\begin{array}{l}\text { Gitman (2010); Ehrnardt e Brignam } \\
\text { (2012) }\end{array}$ \\
\hline \multirow{2}{*}{$\mathrm{PC} / \mathrm{CT}$} & Passivo Circulante & \multirow[t]{2}{*}{ Matarazzo (2010); Silva (2012) } \\
\hline & Capitais de Terceiros & \\
\hline \multirow{2}{*}{$\mathrm{E} / \mathrm{CMV}$} & Estoques & \multirow[t]{2}{*}{ Souza (2007); Silva (2012) } \\
\hline & Custo das Merca donias Vendidas & \\
\hline \multirow{2}{*}{$\mathrm{CR} / \mathrm{V}$} & Contas a Receber & \multirow{2}{*}{$\begin{array}{l}\text { Souza (2007); Gitman (2010); Ehrhardt e } \\
\text { Brigham (2012) }\end{array}$} \\
\hline & Vendas & \\
\hline \multirow{2}{*}{$\mathrm{V} / \mathrm{AT}$} & Vendas Liquidas & \multirow[t]{2}{*}{ Matarazzo (2010); Silva (2012) } \\
\hline & Ativo & \\
\hline \multirow{2}{*}{$\mathrm{ROA}$} & Lucro Líquido & \multirow{2}{*}{$\begin{array}{l}\text { Souza (2007); Gitman (2010); Ehrhardt e } \\
\text { Brigham (2012) }\end{array}$} \\
\hline & Ativo & \\
\hline
\end{tabular}




\begin{tabular}{|l|c|l|}
\hline MB & $\frac{\text { Lucro Bruto }}{\text { Receita Líquida }}$ & $\begin{array}{l}\text { Souza (2007); Gitman (2010); Ehrhardt e } \\
\text { Brigham (2012) }\end{array}$ \\
\hline LPA & Lucro Líquido & Souza (2007); Gitman (2010) \\
\cline { 2 - 3 } & Número de Ações Emitidas & \\
\hline
\end{tabular}

Fonte: Dados da pesquisa.

Por meio de tercis foram determinados os indicadores padrão para o enquadramento de cada uma das empresas em seções, em que o primeiro, segundo e terceiro tercis foram considerados para as seções da lógica paraconsistente, respectivamente. As três seções utilizadas na lógica paraconsistente foram: $\mathrm{S}_{1}$, a qual traduz as condições em que o indicador é desfavorável ao pesquisador e/ou auxiliares; $\mathrm{S}_{2}$, que traduz as condições em que o indicador é indiferente ao pesquisador e/ou auxiliares; e por fim, $\mathrm{S}_{3}$ que traduz as condições em que o indicador é favorável ao pesquisador e/ou auxiliares (CARVALHO; ABE, 2011). O quadro 2 faz a representação dos tercis da Lógica Paraconsistente, os quais foram também representados nos questionários.

Quadro 2 - Representação dos tercis utilizados como seções da Lógica Paraconsistente para questionários

Painel A: Indicadores-padrão para indicadores que quanto maior melhor (liquidez geral, liquidez corrente, liquidez seca, liquidez imediata, giro do ativo, rentabilidade do ativo, margem bruta, lucro por ação, dividendos por ação e preço/lucro)

\begin{tabular}{|c|c|c|c|}
\hline & Baixo & Médio & Alto \\
\hline Máximo & $1^{\mathrm{o}}$ Tercil $\left(\mathrm{S}_{3}\right)$ & $2^{\circ}$ Tercil $\left(\mathrm{S}_{2}\right)$ & $3^{\circ}$ Tercil $\left(\mathrm{S}_{1}\right)$ \\
\hline
\end{tabular}

Painel B: Indicadores-padrão para indicadores que quanto menor melhor (composição do endividamento, prazo médio de renovação de estoques e prazo médio de recebimento de vendas)

\begin{tabular}{|c|c|c|c|}
\hline & Baixo & Médio & Alto \\
\hline Mínimo & $1^{\mathrm{o}}$ Tercil $\left(\mathrm{S}_{1}\right)$ & $2^{o}$ Tercil $\left(S_{2}\right)$ & $3^{\circ}$ Tercil $\left(S_{3}\right)$ \\
\hline
\end{tabular}

(S1) Traduz condições em que o fator é desfavorável

\begin{tabular}{|c|c|}
\hline (a) Grau de Evidenciação Favorável & (b) Grau de Evidenciação Desfavorável \\
\hline & \\
\hline
\end{tabular}

$\left(S_{2}\right)$ Traduz condições em o fator é indiferente

\begin{tabular}{|l|l|}
\hline (a) Grau de Evidenciação Favorável & (b) Grau de Evidenciação Desfavorável \\
\hline & \\
\hline
\end{tabular}

$\left(\mathbf{S}_{3}\right)$ Traduz condições em o fator é favorável

\begin{tabular}{l|l} 
(a) Grau de Evidenciação Favorável & (b) Grau de Evidenciação Desfavorável
\end{tabular}

Fonte: Elaborado pelos autores.

Para a determinação do valor-padrão da distribuição, normalmente são utilizadas medidas estatísticas como média aritmética, moda, mediana, quartis, decis, ou ainda percentil (SILVA, 2012). A escolha especificamente por tercis se deve a necessidade do estabelecimento das seções da Lógica Paraconsistente Anotada.

O enquadramento das empresas nas seções para cada indicador realizado pelos tercis depende se os indicadores são de quanto maior melhor, ou quanto menor melhor. De acordo com essa lógica, os indicadores pertencentes ao Painel A localizados no $1^{\circ}$ tercil caracterizamse como desfavoráveis e aquelas que estão alocadas no $3^{\circ}$ tercil são considerados favoráveis. 
Em relação aos indicadores do Painel $\mathrm{B}$ que estão no $1^{\circ}$ tercil, contrariamente são favoráveis às empresas, enquanto que as empresas do $3^{\circ}$ tercil são desfavoráveis. As empresas as quais fazem parte do $2^{\circ}$ tercil, tanto no Painel A quanto no Painel B apresentam tais indicadores alocados como razoáveis.

O enquadramento das empresas foi realizada com o uso de três (3) equipes de especialistas. Cada equipe era composta por dois (2) professores/pesquisadores pertencentes aos Programas de Pós-Graduação em Ciências Contábeis (PPGCCs) das seguintes instituições de ensino superior (IES): Universidade Federal do Paraná (UFPR), Universidade Federal de Santa Catarina (UFSC) e Universidade Regional de Blumenau (FURB). Cada pesquisador elegeu um auxiliar dentre seus orientandos de mestrado e doutorado. Assim, cada uma das 3 IES envolvidas participou com uma equipe de 4 integrantes. Simbolicamente pode estabelecer o conjunto $\left\{\mathrm{P}_{1}, \mathrm{P}_{2}, \mathrm{~A}_{1}, \mathrm{~A}_{2}\right\}$, onde $\mathrm{P}_{1}$ e $\mathrm{P}_{2}$ são os professores/pesquisadores e $\mathrm{A}_{1}$ e $\mathrm{A}_{2}$ são auxiliares.

As avaliações de cada instituição envolvida foram efetuadas pelo seguinte conjunto de pares ordenados: $\left\{\left(\mathrm{P}_{1}, \mathrm{~A}_{1}\right),\left(\mathrm{P}_{1}, \mathrm{~A}_{2}\right),\left(\mathrm{P}_{2}, \mathrm{~A}_{2}\right),\left(\mathrm{P}_{2}, \mathrm{~A}_{2}\right)\right\}$. A intenção deste tipo de composição visava buscar algum padrão subjacente nas avaliações.

Dos avaliadores dependeu a indicação de graus de indicação dos fatores em suas três possibilidades: favorável, indiferente e desfavorável $\left(\mathrm{S}_{1}, \mathrm{~S}_{2}, \mathrm{~S}_{3}\right)$, associando em cada um deles um grau de crença favorável e outro de crença desfavorável, com valores entre 0 e 1.

O quartil de pertinência de cada empresa em cada variável foi anteriormente determinado, restando, pois, o enquadramento das seções com os indicadores calculados e mensuração dos graus pelos respondentes. Em seguida foram aplicados os operadores MÁX e MIN da Lógica Paraconsistente Anotada, conforme Quadro 3, em que o Grupo $\alpha$ é constituído do Pesquisador $P_{i}$ e auxiliar $A_{i}$ e o Grupo $\beta$ agrega o Pesquisador $P_{j}$ e auxiliar $A_{j}$.

Quadro 3 - Esquema da aplicação dos operadores MÁX e MÍN

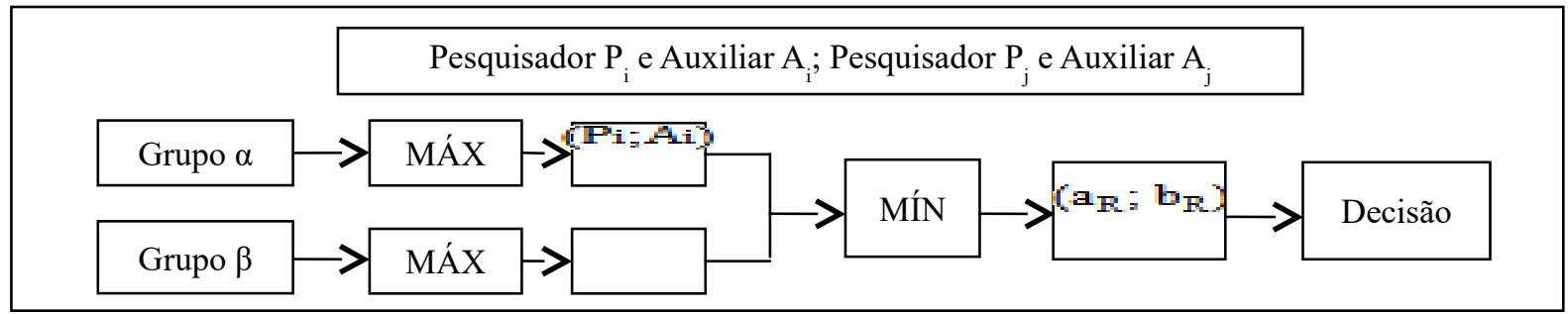

Fonte: Adpatado de Carvalho e Abe (2011).

O operador de maximização é aplicado do grau de certeza dentro do conjunto de anotações para cada Grupo separadamente, ou seja, escolhe-se simultaneamente o maior grau de evidência favorável e o menor grau de evidência desfavorável. Assim, a aplicação do MÁX se faz entre as opiniões de especialistas que não são todos determinantes, ou seja, basta a opinião favorável de somente um especialista para que o resultado seja considerado satisfatório (CARVALHO; ABE, 2011). Em contrapartida, o operador MIN consiste na minimização do grau de certeza dentro de um conjunto de anotações, com a escolha do menor grau de evidência favorável e maior grau de evidência desfavorável. Este operador de minimização é aplicado entre os máximos obtidos dos Grupos A e B. Por último foi calculado o baricentro de cada empresa e este foi graficado juntamente com as demais empresas em estudo.

Em específico, uma boa avaliação, sem o viés da inconsistência ou paracompleteza, possui grande aderência ao segmento de reta que liga os pares ordenados $(0,1)$ a $(1,0)$, ou seja, os valores avaliados e enquadrados no reticulado das anotações, possuindo assim quase ou nenhuma inconsistência $(1,1)$ ou paracompleteza $(0,0)$. Para gerar o grau de viabilidade $(\mathrm{GV})$ das empresas a partir da sua posição no reticulado, dado pelo par ordenado (x,y), será 
projetado sobre a reta $x+y-1=0$. Para tanto, será inicialmente calculada distância do ponto $(\mathrm{x}, \mathrm{y})$ até a reta pela equação $d(P, r)=\frac{\left|a x_{0}+b y_{0}-c\right|}{\sqrt{a^{2}+b^{2}}}$, que neste caso será dado por $d(P, r)=\frac{|x-y-1|}{\sqrt{2}}$. Para a obtenção da localização do ponto projetado, será calculada a distância euclidiana entre $(\mathrm{x}, \mathrm{y})$ e o ponto $(0,1)$ que será chamada de $\mathrm{d}^{+}$, pois irá apresentar a distância bruta do ponto $(\mathrm{x}, \mathrm{y})$ ao cenário de viabilidade em $\mathrm{V}=(1,0)$. De similar modo será calculada a distância bruta entre $(\mathrm{x}, \mathrm{y})$ e o cenário de inviabilidade $(0,1)$. Por meio do Teorema de Pitágoras serão calculados $d^{\text {via }} \mathrm{e}^{d^{i n v}}$, que serão as distâncias do ponto projetado sobre a reta, até o ponto $(0,1)$ e $(1,0)$, ou seja, os cenários de viabilidade e inviabilidade. Em termos matemáticos, será: $d^{v i a}=\sqrt{\left(d^{+}\right)^{2}+(d(P, r))^{2}} \mathrm{e}^{d^{i n v}}=\sqrt{\left(d^{-}\right)^{2}+(d(P, r))^{2}}$. Finalmente, o grau de viabilidade para será calculado: $G V_{i}=\frac{d_{i}^{\text {inv }}}{d_{i}^{\text {via }}+d_{i}^{\text {inv }}}$. Logicamente, a cada par de avaliadores haverá um novo cenário que será sintetizado pela média.

\section{RESULTADOS E DISCUSSÕES}

A seguir são apresentados os reticulados para cada ano do período de 2011 à 2018 , obtidos por meio da lógica paraconsistente. Por motivo estético, serão apresentados apenas os resultados referentes ao ano de 2018, participando que os demais anos seguem a mesma construção. As tabelas 01, 02 e 03 trazem os resultados do ano de 2015, do enquadramento feito pelos especialistas da UFSC. Na Tabela 01 estão as combinações feitas pelos dois grupos de avaliadores especialistas da FURB, ou seja, os professores $(\mathrm{P})$ e alunos $(\mathrm{A})$ em que $\mathrm{P}=\{\mathrm{A} 1$, $\mathrm{A} 2\}$ e $\mathrm{A}=\{\mathrm{B} 1, \mathrm{~B} 2\}$.

Tabela 01: Avaliação paraconsistente; ano 2018; especialistas da FURB.

\begin{tabular}{l|c|c|l|c|c}
\hline \multicolumn{3}{c}{ FURB - 2018 (A1 e B1) } & \multicolumn{3}{c}{ FURB - 2018 (A1 e B2) } \\
\hline Ferbasa & 0.695 & 0.338 & Ferbasa & 0.588 & 0.442 \\
\hline Fibam & 0.502 & 0.534 & Fibam & 0.412 & 0.635 \\
\hline Gerdau & 0.471 & 0.501 & Gerdau & 0.484 & 0.495 \\
\hline Gerdau Met & 0.417 & 0.558 & Gerdau Met & 0.415 & 0.561 \\
\hline Mangels Indl & 0.506 & 0.522 & Mangels Indl & 0.468 & 0.555 \\
\hline Panatlantica & 0.598 & 0.448 & Panatlantica & 0.619 & 0.410 \\
\hline Paranapanema & 0.503 & 0.502 & Paranapanema & 0.419 & 0.588 \\
\hline Sid Nacional & 0.582 & 0.408 & Sid Nacional & 0.582 & 0.435 \\
\hline Tekno & 0.454 & 0.550 & Tekno & 0.408 & 0.603 \\
\hline Usiminas & 0.399 & 0.604 & Usiminas & 0.375 & 0.658 \\
\hline \multicolumn{2}{|c|}{ FURB - 2018 (A2 B1) } & & & 0.596 & 0.408 \\
\hline Ferbasa & 0.668 & 0.355 & Ferbasa & 0.388 & 0.635 \\
\hline Fibam & 0.448 & 0.568 & Fibam & 0.522 & 0.482 \\
\hline Gerdau & 0.528 & 0.466 & Gerdau & 0.411 & 0.578 \\
\hline Gerdau Met & 0.415 & 0.562 & Gerdau Met & 0.515 & 0.497 \\
\hline Mangels Indl & 0.545 & 0.492 & Mangels Indl & 0.623 & 0.404 \\
\hline Panatlantica & 0.642 & 0.395 & Panatlantica & 0.408 & 0.592 \\
\hline Paranapanema & 0.448 & 0.581 & Paranapanema & 0.573 & 0.412 \\
\hline Sid Nacional & 0.558 & 0.428 & Sid Nacional & (A2 B2) \\
\hline
\end{tabular}




\begin{tabular}{l|l|l|l|l|l}
\hline Tekno & 0.441 & 0.578 & Tekno & 0.403 & 0.597 \\
\hline Usiminas & 0.363 & 0.646 & Usiminas & 0.362 & 0.665 \\
\hline
\end{tabular}

Fonte: Dados da pesquisa.

A seguir apresenta-se as combinações feitas pelos dois grupos de avaliadores especialistas da UFPR, ou seja, os professores (P) e alunos (A) em que $\mathrm{P}=\{\mathrm{E} 1, \mathrm{E} 2\}$ e $\mathrm{A}=\{\mathrm{F} 1$, F2\}.

Tabela 02: Avaliação paraconsistente; ano 2015; especialistas da UFSC

\begin{tabular}{|c|c|c|c|c|c|}
\hline \multicolumn{3}{|c|}{$\overline{U F P R ~-~} 2018$ (C1 e D1) } & \multicolumn{3}{|c|}{ UFPR - 2018 (C1 e D2) } \\
\hline Ferbasa & 0.604 & 0.227 & Ferbasa & 0.760 & 0.265 \\
\hline Fibam & 0.562 & 0.412 & Fibam & 0.527 & 0.415 \\
\hline Gerdau & 0.500 & 0.458 & Gerdau & 0.515 & 0.431 \\
\hline Gerdau Met & 0.515 & 0.438 & Gerdau Met & 0.492 & 0.485 \\
\hline Mangels Indl & 0.585 & 0.385 & Mangels Indl & 0.627 & 0.404 \\
\hline Panatlantica & 0.619 & 0.304 & Panatlantica & 0.650 & 0.296 \\
\hline Paranapanema & 0.573 & 0.354 & Paranapanema & 0.525 & 0.400 \\
\hline Sid Nacional & 0.623 & 0.219 & Sid Nacional & 0.619 & 0.265 \\
\hline Tekno & 0.581 & 0.273 & Tekno & 0.612 & 0.315 \\
\hline Usiminas & 0.535 & 0.415 & Usiminas & 0.550 & 0.415 \\
\hline \multicolumn{3}{|c|}{ UFPR - 2018 (C2 e D1) } & \multicolumn{3}{|c|}{ UFPR - 2018 (C2 e D2) } \\
\hline Ferbasa & 0.538 & 0.385 & Ferbasa & 0.635 & 0.381 \\
\hline Fibam & 0.588 & 0.396 & Fibam & 0.555 & 0.555 \\
\hline Gerdau & 0.535 & 0.396 & Gerdau & 0.558 & 0.369 \\
\hline Gerdau Met & 0.519 & 0.385 & Gerdau Met & 0.492 & 0.432 \\
\hline Mangels Indl & 0.638 & 0.323 & Mangels Indl & 0.665 & 0.331 \\
\hline Panatlantica & 0.627 & 0.312 & Panatlantica & 0.685 & 0.305 \\
\hline Paranapanema & 0.581 & 0.369 & Paranapanema & 0.535 & 0.381 \\
\hline Sid Nacional & 0.619 & 0.300 & Sid Nacional & 0.708 & 0.296 \\
\hline Tekno & 0.538 & 0.358 & Tekno & 0.558 & 0.358 \\
\hline Usiminas & 0.550 & 0.381 & Usiminas & 0.570 & 0.382 \\
\hline
\end{tabular}

Fonte: Dados da pesquisa

Na Tabela 03 estão as combinações feitas pelos dois grupos de avaliadores especialistas da UFSC, ou seja, os professores (P) e alunos (A) em que $\mathrm{P}=\{\mathrm{E} 1, \mathrm{E} 2\}$ e $\mathrm{A}=\{\mathrm{F} 1, \mathrm{~F} 2\}$.

Tabela 03: Avaliação paraconsistente; ano 2018; especialistas da UFSC

\begin{tabular}{|c|c|c|c|c|c|}
\hline \multicolumn{3}{|c|}{ UFSC - 2018 (E1 e F1) } & \multicolumn{3}{|c|}{ UFSC - 2018 (E1 e F2) } \\
\hline Ferbasa & 0.493 & 0.401 & Ferbasa & 0.492 & 0.419 \\
\hline Fibam & 0.276 & 0.599 & Fibam & 0.348 & 0.604 \\
\hline Gerdau & 0.484 & 0.434 & Gerdau & 0.440 & 0.431 \\
\hline Gerdau Met & 0.336 & 0.523 & Gerdau Met & 0.278 & 0.565 \\
\hline Mangels Indl & 0.410 & 0.417 & Mangels Indl & 0.484 & 0.438 \\
\hline Panatlantica & 0.579 & 0.338 & Panatlantica & 0.548 & 0.376 \\
\hline Paranapanema & 0.282 & 0.600 & Paranapanema & 0.264 & 0.657 \\
\hline Sid Nacional & 0.482 & 0.355 & Sid Nacional & 0.581 & 0.376 \\
\hline Tekno & 0.407 & 0.494 & Tekno & 0.386 & 0.517 \\
\hline Usiminas & 0.235 & 0.645 & Usiminas & 0.218 & 0.710 \\
\hline \multicolumn{3}{|c|}{ UFSC - 2018 (E2 e F1) } & \multicolumn{3}{|c|}{ UFSC - 2018 (E2 e F2) } \\
\hline Ferbasa & 0.452 & 0.429 & Ferbasa & 0.439 & 0.444 \\
\hline Fibam & 0.247 & 0.631 & Fibam & 0.304 & 0.608 \\
\hline
\end{tabular}




\begin{tabular}{l|r|r|l|r|r}
\hline Gerdau & 0.456 & 0.393 & Gerdau & 0.382 & 0.439 \\
\hline Gerdau Met & 0.345 & 0.472 & Gerdau Met & 0.260 & 0.570 \\
\hline Mangels Indl & 0.374 & 0.443 & Mangels Indl & 0.406 & 0.466 \\
\hline Panatlantica & 0.554 & 0.339 & Panatlantica & 0.518 & 0.377 \\
\hline Paranapanema & 0.269 & 0.588 & Paranapanema & 0.236 & 0.675 \\
\hline Sid Nacional & 0.399 & 0.398 & Sid Nacional & 0.445 & 0.418 \\
\hline Tekno & 0.349 & 0.524 & Tekno & 0.321 & 0.548 \\
\hline Usiminas & 0.196 & 0.655 & Usiminas & 0.172 & 0.706 \\
\hline
\end{tabular}

Fonte: dados da pesquisa.

Ao cabo de 12 análises para cada ano, a posição de cada empresa foi reduzida a apenas um par ordenado $(\mathrm{x}, \mathrm{y})$, trazendo o grau de evidência favorável $(\mathrm{x})$ e seu grau de evidência desfavorável (y). Os valores foram sintetizados usando-se a média das ordenadas e abscissas. O resultado final para o período 2011-2018 está na Figura 3.

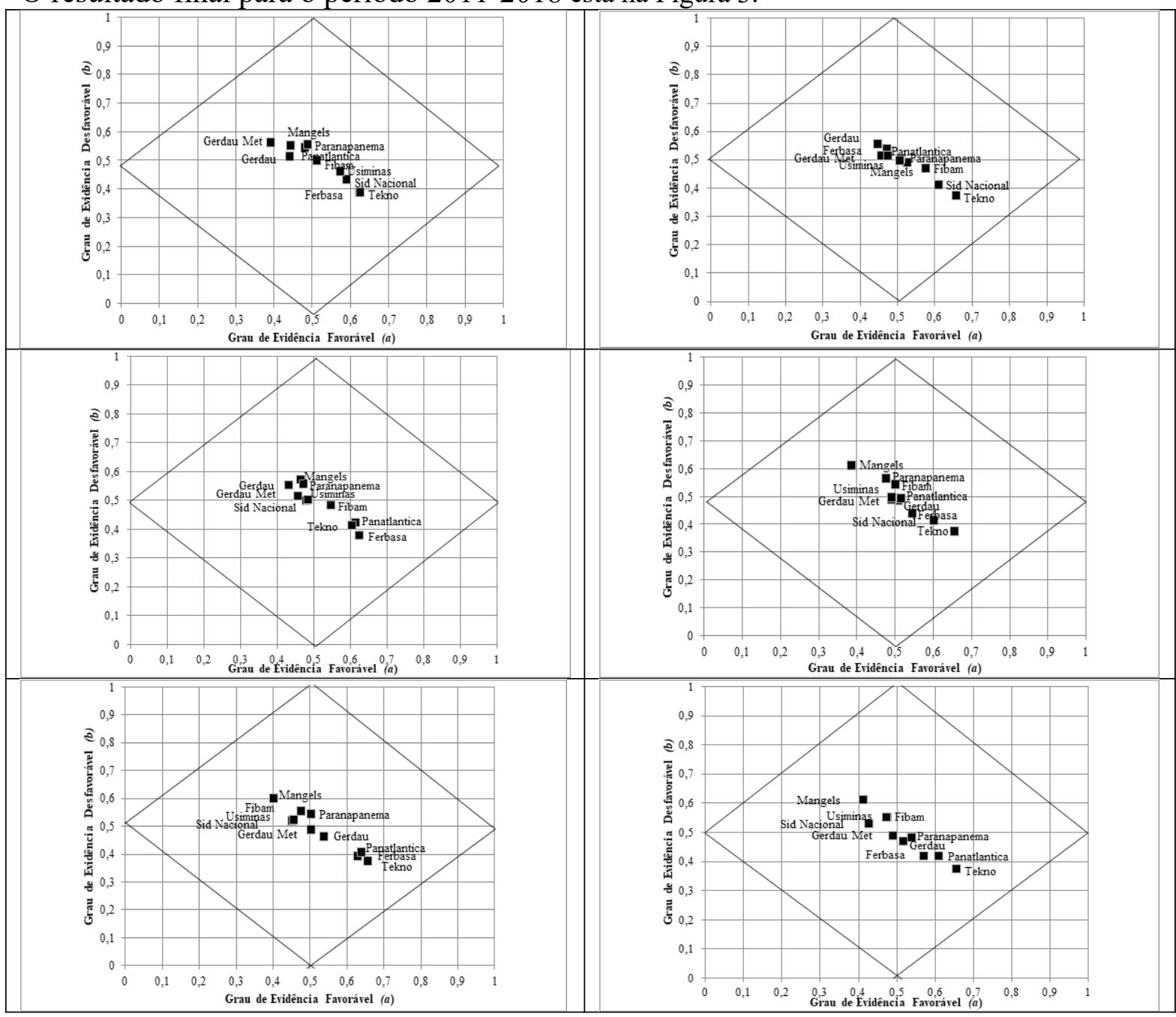




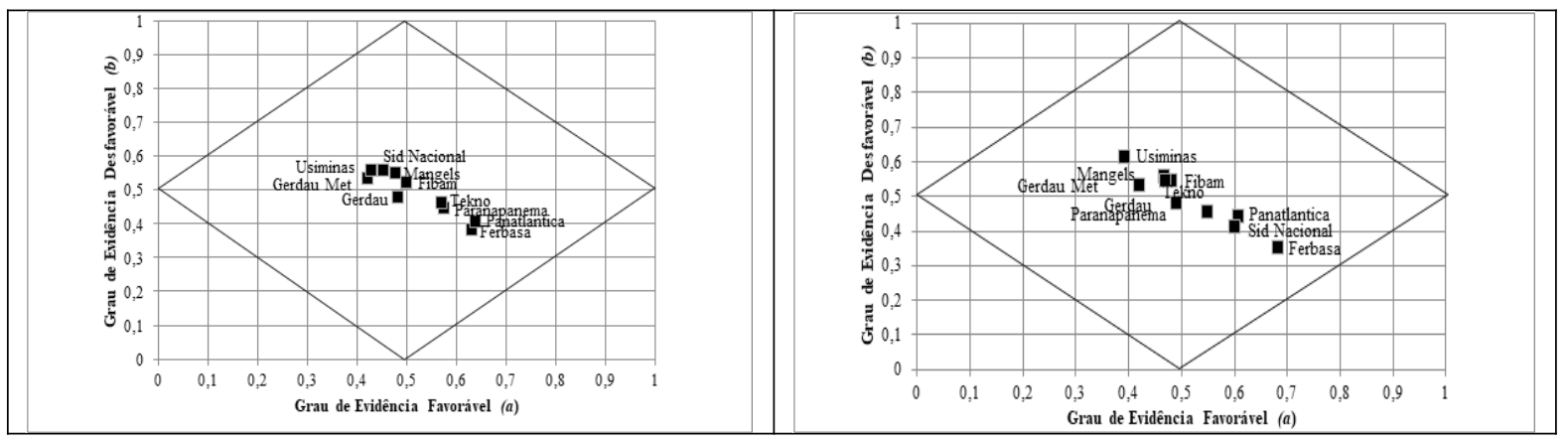

Fonte: Dados da pesquisa

Figura 3 - Posicionamento contábil das empresas nos reticulados - período 2011/18

$\mathrm{Na}$ Figura 3, a posição contábil das empresas entre os anos de 2011 a 2018 e deve ser entendido pelos gráficos pareados: 2011/12, 2013/14, 2015/16 e 2017/18. No primeiro gráfico, as empresas Tekno e Ferbasa apresentaram as melhores posições. Este resultado é condizente com conclusões obtidas em anos anteriores, os quais foram verificados no estudo de Kroenke (2009), para o período de 2004 a 2008, que as duas empresas também apresentaram as primeiras posições. A empresa Usiminas se apresenta em terceira posição, ou seja, está alocada entre as melhores. Em contrapartida, a empresa Mangels apresenta-se entre as últimas colocadas.

No segundo gráfico, apesar da empresa Ferbasa se apresentar entre as melhores posições em 2011, especificamente perde muito de seu posicionamento frente as demais empresas do subsetor em 2012. A crise global interferiu o desempenho da Ferbasa, afetando seus custos de maneira negativa e reduzindo o seu lucro líquido. Estas consequências podem justificar a sua mudança de posicionamento em relação a Siderurgia e Metalurgia. Deve-se destacar também a perda de posicionamento da Usiminas, talvez não tão significativa quanto a Ferbasa, mas é perceptível, uma vez que teve um distanciamento frente a região de viabilidade quando comparada a sua posição no ano de 2011.

Em relação a Paranapanema, pode-se observar uma melhora em seu posicionamento econômico-financeiro. Conforme resultados do exercício de 2012, a empresa apresenta maiores índices de receita bruta, volume de vendas, lucro líquido, margem líquida e patrimônio líquido quando comparado ao ano de 2008. Deve-se destacar que a Mangels também apresenta melhora em seu posicionamento econômico-financeiro em 2012.

O terceiro gráfico faz a representação do posicionamento das empresas no reticulado para o ano de 2013, nele a Ferbasa retoma seu posicionamento, como também a empresa Panatlantica assume novas posições, estando entre as melhores juntamente com a Tekno e a Ferbasa. Em contrapartida, a empresa Sid Nacional, a qual estava alocada entre as melhores nos anos de 2011 e 2012, perde posição considerável na Siderurgia e Metalurgia. A Mangels, a qual apresentou melhora no posicionamento, volta a estar entre as piores posições, como sucedeu em 2011. Pode ser verificado que a empresa Panatlantica, a qual estava em posicionamentos desfavoráveis nos anos de 2011 e 2012, apresenta um avanço considerável em sua posição para o ano de 2013.

Em 2011, pode-se notar que a empresa Sid Nacional tem uma grande melhora em seu posicionamento econômico-financeiro. Contudo, percebe-se que a Fibam tem uma perda considerável em seu posicionamento quando comparados aos anos de 2011 e 2012. Novamente registra-se que a Mangels está consideravelmente em última posição, aproximando-se mais da região de inviabilidade do que as demais empresas da Siderurgia e Metalurgia. $\mathrm{O}$ quinto gráfico mostra o reticulado com o posicionamento das empresas no ano de 2015.

Em 2015, as empresas Tekno, Ferbasa e Panatlantica continuam apresentando as melhores posições desde 2013. Contudo, como no ano de 2013, é perceptível que novamente 
a Sid Nacional passou a ter posicionamento desfavorável na Siderurgia e Metalurgia para o ano de 2015. Em quase todos os anos anteriores da pesquisa, a Mangels se apresenta em última posição. Especificamente neste ano, a Mangels não conseguia prosseguir em seu nível de crescimento, devido a reflexos da crise internacional e também da crise europeia, identificada em 2014. Pode-se verificar também que a Fibam mantém nas últimas posições. Isto pode ser justificado pelo agravamento da crise europeia, em que especificamente na Fibam provocou retração nas vendas, e por consequência com posterior redução na produção no ano de 2015.

No sexto gráfico, especificamente em relação a Paranapanema, é perceptível que esta tem uma melhora em seu posicionamento econômico-financeiro a partir de 2013. Em contrapartida, com exceção do ano de 2014, a Sid Nacional passou a estar entre os piores posicionamentos da Siderurgia e Metalurgia. Em relação a Mangels, está novamente com o pior posicionamento. No ano de 2016, devido a suas dívidas bancárias, a Mangels decidiu implementar um processo de venda de ativos. O sétimo gráfico faz a representação do posicionamento das empresas no reticulado para o ano de 2017.

No período de 2011 a 2016 foi constatado que a Tekno se apresentava em primeiras posições. Contudo, no ano de 2017, pode ser observado que seu posicionamento é reduzido, perdendo 4 posições. Este resultado da empresa pode ser consequência da crise econômica do país, a qual decorreu em meados de 2017. Neste ano, a Tekno apresentou uma queda considerável de fornecimento aos setores de eletrodoméstico e automotivo.

Como já verificado, a Usiminas perdeu posição de forma progressiva após o ano de 2011, em que especificamente no ano de 2017 assumiu última posição. Esta mudança de posição em quase todo o período se deve a Usiminas ser impactada tanto pela crise global, como também pela crise econômica nacional. Similarmente, a Sid Nacional também perdeu posicionamento novamente.

No oitavo e último gráfico, de maneira geral, é perceptível que a empresa Mangels está em últimas posições em quase todos os anos. Possivelmente, seu posicionamento se deve às dificuldades financeiras que teve já na crise global, como também com a crise do aço, a qual gerou significativos prejuízos para a empresa em 2014 e 2015. Em 2018, fica evidenciado que a Tekno tem uma perda significativa em seu posicionamento econômico-financeiro, devido a crise econômica do país. Em contrapartida, a Sid Nacional alcançou posicionamento favorável, conforme também tinha apresentado nos anos de 2011 e 2012.

Por último tem-se o grau de viabilidade geral das empresas analisadas. Na tabela 04 estão elencados o GV de auferido por cada IES no período estudado e sua posição no ranking de viabilidade.

Tabela 04: Grau de Viabilidade das empresas analisadas e sua posição no ranking.

\begin{tabular}{l|c|c|c|c|c|c}
\hline \multicolumn{1}{c|}{ Empresa } & GV-UFSC & Posição & GV-UFPR & Posição & GV-FURB & Posição \\
\hline Ferbasa & 0.541901 & $1^{\mathrm{a}}$ & 0.691138 & $1^{\mathrm{a}}$ & 0.586226 & $1^{\mathrm{a}}$ \\
\hline Fibam & 0.327728 & $8^{\mathrm{a}}$ & 0.596294 & $6^{\mathrm{a}}$ & 0.415433 & $10^{\mathrm{a}}$ \\
\hline Gerdau & 0.498995 & $5^{\mathrm{a}}$ & 0.552244 & $10^{\mathrm{a}}$ & 0.533942 & $3^{\mathrm{a}}$ \\
\hline Gerdau met & 0.459769 & $6^{\mathrm{a}}$ & 0.562208 & $8^{\mathrm{a}}$ & 0.477668 & $6^{\mathrm{a}}$ \\
\hline Mangels Indl & 0.445731 & $7^{\mathrm{a}}$ & 0.617089 & $5^{\mathrm{a}}$ & 0.455264 & $7^{\mathrm{a}}$ \\
\hline Panatlantica & 0.510043 & $3^{\mathrm{a}}$ & 0.636549 & $4^{\mathrm{a}}$ & 0.546707 & $2^{\mathrm{a}}$ \\
\hline Paranapanema & 0.311868 & $9^{\mathrm{a}}$ & 0.590777 & $7^{\mathrm{a}}$ & 0.434327 & $8^{\mathrm{a}}$ \\
\hline Sid Nacional & 0.500048 & $4^{\mathrm{a}}$ & 0.658402 & $3^{\mathrm{a}}$ & 0.488654 & $5^{\mathrm{a}}$ \\
\hline Tekno & 0.523108 & $2^{\mathrm{a}}$ & 0.667193 & $2^{\mathrm{a}}$ & 0.524567 & $4^{\mathrm{a}}$ \\
\hline Usiminas & 0.299522 & $10^{\mathrm{a}}$ & 0.557875 & $9^{\mathrm{a}}$ & 0.417981 & $9^{\mathrm{a}}$ \\
\hline
\end{tabular}

Fonte: dados da pesquisa 
Há de se destacar que a correlação de Kendall entre o GV atribuído pela UFSC e o da FURB é de 90,3\% (significativa ao nível de 1\%). Entre a UFSC e UFPR é de 59,9\% não apresentando significância. De similar modo a relação entre UFPR e FURB a correlação é de $57,7 \%$, também sem significância.

Entre a avaliação da UFSC e FURB, o coeficiente de correlação ordinal de Kendall registrou 77,8\% entre as posições no ranking, sendo significante ao nível de $1 \%$. A correlação ordinal entre os rankings da UFPR e UFSC registrou $60,0 \%$, significativa ao nível de 5\%. Por último, entre UFPR e FURB ficou em 37,8\%, não apresentando significância.

\section{CONCLUSÃO}

O objetivo deste artigo foi verificar qual a influência dos indicadores econômicofinanceiros no posicionamento econômico-financeiro das empresas de Siderurgia e Metalurgia listadas na BM\&FBovespa, no período de 2011 à 2018. Por meio da aplicação da Lógica Paraconsistente, foi possível determinar os posicionamentos econômico-financeiros. A metodologia caracterizou-se como descritiva, com análise documental e também abordagem quantitativa.

Como resultado principal, verificou-se que a liquidez corrente influenciou negativamente no posicionamento econômico-financeiro da Siderurgia e Metalurgia, em oposição às influências verificadas em outros indicadores como de liquidez seca, rentabilidade sobre os ativos, giro do ativo e prazo médio de renovação de estoques, as quais foram verificadas influências positivas. Desta forma, possivelmente a liquidez corrente destas empresas é debilitada pela renovação dos estoques, uma vez que a não consideração dos estoques, por meio da liquidez seca, influenciou positivamente o posicionamento das empresas.

Portanto, ressalta-se que possivelmente a Siderurgia e Metalurgia necessita cada vez mais de uma logística mais eficiente, a qual depende também da eficiência das operações de transporte em toda a cadeia. Assim, conforme a importância do aprimoramento no subsetor, ressalta-se que possivelmente haja maiores necessidades de equipamentos modernos, como também a implementação de sistemas de gestão mais avançados.

Estes resultados reforçam a importância de novas estratégias para este subsetor, com a finalidade de melhorar tanto a saúde financeira, como o posicionamento econômicofinanceiro dessas empresas. Além disso, visto a consistência da Lógica Paraconsistente à determinação dos posicionamentos das empresas, as quais não estão alocadas em regiões nem de paracompleteza e nem de inconsistência, essas evidências mostram que a Lógica Paraconsistente pode ser aplicável à área da contabilidade, uma vez que poucos estudos utilizaram essa metodologia em Ciências Contábeis.

\section{AGRADECIMENTO}

Os autores agradecem o auxílio financeiro recebido do Conselho Nacional de Desenvolvimento Científico e Tecnológico (CNPq).

\section{REFERÊNCIAS BIBLIOGRÁFICAS}

[1] AGUiAR, A. B.; CORRAR, L. J.; BATISTElla, F. D. Adoção de práticas de governança corporativa e o comportamento das ações na Bovespa: evidências empíricas. Revista de Administração, v. 39, n. 4, p. 338-347, 2004.

[2] BM\&FBOVESPA. Empresas listadas. 2016. Disponível em: < http://www.bmfbovespa.com.br/pt br/produtos/listados-a-vista-e-derivativos/rendavariavel/empresas-listadas.htm>. Acesso em: 17 mar. 2017. 
[3] BORTOLUZZI, Sandro César et al. Avaliação de desempenho econômico-financeiro da empresa Marel Indústria de Móveis SA: a contribuição da metodologia multicritério de apoio à decisão construtivista (MCDA-C). (Dissertação de Mestrado). Florianópolis: Universidade Federal de Santa Catarina, 2009.

[4] CARVALHO, Fábio Romeu de. Lógica paraconsistente aplicada em tomadas de decisão: uma abordagem para a administração de universidades. São Paulo: Aleph, 2002.

[5] CARVALHO, Fábio Romeu de; BRUNSTEIN, Israel; ABE, Jair Minoro. Paraconsistent Annotated Logic in Viability Analysis: an Approach to Product Launching. In: DUBOIS, Daniel M. (Ed.). AIP Conference Proceedings. AIP, 2004. p. 282-291.

[6] CARVAlHO, Fábio Romeu de; ABE, Jair Minoro. Tomadas de decisão com ferramentas da lógica paraconsistente anotada: método paraconsistente de decisão. São Paulo: Blucher, 2011.

[7] CONFEDERAÇÃO NACIONAL DOS METALÚRGICOS (CNM). A indústria siderúrgica e da metalurgia básica no Brasil. Diagnóstico e Propostas elaboradas pelos Metalúrgicos da $2012 . \quad$ CUT. Disponível em: $<$ http://www.cnmcut.org.br/midias/arquivo/185-diagnostico-siderurgia.pdf $>$. Acesso em: 16 abr. 2017.

[8] EHRHARDT, Michael C; BRIGHAM, Eugene F. Administração financeira: teoria e prática. 2. ed. São Paulo: Cengage Learning, 2012.

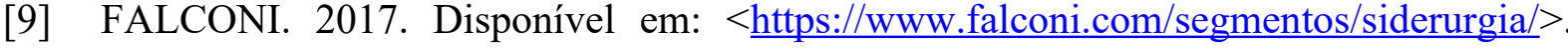
Acesso em 8 dez. 2017.

[10] FALQUETE, Vera Lucia Marchiori. Utilização de lógica paraconsistente para tratamento de inconsistências em sistemas de raciocínio baseado em casos. (Tese de Doutorado). Programa de Pós-Graduação em Informática Aplicada. Curitiba: Pontifícia Universidade do Paraná, 2004.

[11] FERNANDES, Francisco Carlos; MAZZIONI, Sady. A correlação entre a remuneração dos executivos e o desempenho de empresas brasileiras do setor financeiro. Contabilidade Vista \& Revista, v. 26, n. 2, p. 41-64, 2015.

[12] FUENMAYOR, Cyndy; ANGULO, Leyla. Indices económicos financieros en la toma de decisiones para empresas del sector farmacéutico del municipio "Jesus Enrique Lossada" del estado zulia". (Trabalho de conclusão de curso). Maracaibo: Universidad Rafael Urdaneta, 2008.

[13] GASPARETTO, Valdirene. O papel da Contabilidade no provimento de Informações para a Avaliação do Desempenho Empresarial. Revista Contemporânea de Contabilidade, v. 1, n. 2, p. 109-122, 2004.

[14] GITMAN, Lawrence J. Princípios de administração financeira. 12. ed. São Paulo: Pearson, 2010.

[15] KROENKE, Adriana. Posicionamento das empresas do setor metal mecânico listadas na Bovespa: uma aplicação do método AHP. 2009. Dissertação (Mestrado em Ciências Contábeis) Centro de Ciências Sociais Aplicadas, Universidade Regional de Blumenau-FURB, Blumenau. 
[16] LEITE, Roberto Rodrigues. Mecanismo para superação das barreiras na implantação da produção mais limpa em pequenas e médias empresas: estudo de múltiplos casos no setor metalúrgico. (Dissertação de Mestrado). São Paulo: Universidade Nove de Julho, 2014.

[17] LIBERTÁ. 2015. Disponível em: $<$ http://www.libertaconsultoria.com.br/atuacao.php?

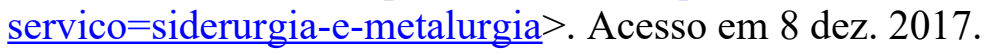

[18] MATARAZZO, Dante C. (Dante Carmine). Análise financeira de balanços: abordagem gerencial. 7. ed. São Paulo: Atlas, 2010.

[19] MINISTÉRIO DE MINAS E ENERGIA (MME). Anuário Estatístico do Setor Metalúrgico. 2011. Disponível em: < http://www.mme.gov.br/documents/10584/1865251/Anuario_Setor_Metalurgico_2011 base 2010.pdf/a27e2c66-9d93-43b1-ae4c-4b105786f0fc >. Acesso em 16 abr. 2017.

[20] MINISTÉRIO DE MINAS E ENERGIA (MME). Anuário Estatístico do Setor Metalúrgico. 2013. Disponível em: < http://www.mme.gov.br/documents/10584/1865251/Anuario_Setor_Metalurgico_2013 base 2012 parte 1.pdf/ac9ca050-9ab7-4e63-8c04-ca13903bfc9e >. Acesso em: 16 abr. 2017.

[21] MINISTÉRIO DE MINAS E ENERGIA (MME). Anuário Estatístico do Setor Metalúrgico. 2016.2 Disponível em: $<$ http://www.mme.gov.br/documents/1138775/1732813/ANU\%C3\%81RIO+METAL $\% \mathrm{C} 3 \% 9 \mathrm{ARGICO}+2016$ vers\%C3\%A3o+3.pdf/9595d304-7072-4313-a190b5b97a10e7a5>. Acesso em: 16 abr. 2017.

[22] POSO, A. T. A siderurgia brasileira e mundial: o desenvolvimento desigual recente. (Tese de Doutorado). Universidade de São Paulo. São Paulo, 2015.

[23] SIDERURGIA BRASIL. Disponível em: http://www.siderurgiabrasil.com.br/portal >. Acesso em 8 dez. 2017.

[24] SILVA, José Pereira da. Análise financeira das empresas. 11. ed. atual. Conforme novas regras contábeis. São Paulo: Atlas, 2012.

[25] SILVA, Caio Assumpção. A relação entre a taxa de câmbio e o preço das exportações: o caso da siderurgia brasileira. (Dissertação de Mestrado). Brasília: Universidade de Brasília, 2014.

[26] SOARES, Maria Aparecida. Análise de indicadores para avaliação de desempenho econômico-financeiro de operadoras de planos de saúde brasileiras: uma aplicação da análise fatorial. (Tese de Doutorado). São Paulo: Universidade de São Paulo, 2006.

[27] SOUZA, Sérgio Luiz de. Indicadores de sucesso e seus reflexos na gestão financeira das sociedades anônimas metal-mecânicas de capital aberto. (Dissertação de Mestrado). Joinville: Universidade do Estado de Santa Catarina, 2007.

[28] THE ECONOMIST. Iron and steel production. 2016. Disponível em: < http://www.economist.com/topics/iron-and-steel-production>. Acesso em: 17 mar. 2017.

[29] TORRES, Cláudio Rodrigo. Sistema inteligente paraconsistente para controle de robôs móveis autônomos. (Tese de Doutorado). Itajubá: Universidade Federal de Itajubá, 2004. 